\title{
Delayed diagnosis of a cesarean scar pregnancy: a case report
}

\author{
Eun Ju Jo, Hyun-Hwa Cha ${ }^{*}$ and Won Joon Seong
}

\begin{abstract}
Background: Cesarean scar pregnancy is rare but may be related to early uterine rupture and may result in massive hemorrhage. Nowadays, most cesarean scar pregnancies are diagnosed early and can be managed properly. However, diagnoses of cesarean scar pregnancies that develop in the obstetrical area are sometimes delayed.

Case presentation: A 28-year-old Asian woman visited our institution because of suspected cesarean scar pregnancy. Ultrasonography and computed tomography confirmed a cesarean scar pregnancy with a live fetus with a crown-rump length of $4.83 \mathrm{~cm}$, corresponding to 11 weeks 6 days of gestation. Initially, we injected $50 \mathrm{mg}$ of methotrexate in the amniotic sac under transabdominal ultrasonographic guidance. However, fetal cardiac activity was still observed 2 days later. We decided to perform open laparotomy because of the possibility of massive bleeding. The gestational sac was removed, as well as most of the trophoblastic tissues that were adherent and invading the wall of the lower uterine segment. She was discharged in good condition 5 days after the operation.

Conclusions: Despite the popular use of ultrasonography in prenatal care, diagnosis of cesarean scar pregnancy is still delayed. Surgical treatment with local methotrexate injection could be an option for the management of advanced cesarean scar pregnancy.
\end{abstract}

Keywords: Ectopic pregnancy, Cesarean scar, Laparotomy, Delayed diagnosis

\section{Background}

Cesarean scar pregnancy (CSP) is the rarest form of ectopic pregnancy and results in implantation of the gestational sac into the fibrous tissue scar of a previous cesarean section. CSP accounts for $6.1 \%$ of ectopic pregnancies, and $0.15 \%$ of pregnancies in which the patient had previously undergone a cesarean section $[1,2]$. It is considered potentially lethal, as it leads to high risks of uterine rupture. Therefore, early diagnosis and prompt treatment are important to reduce maternal morbidity and mortality. Fortunately, appropriate prenatal care using ultrasonography (USG) permits earlier and accurate diagnosis of CSP; therefore, few cases of CSP diagnosed at a gestational age $>10$ weeks have been reported. Here, we report a case of delayed diagnosis of CSP at 11 weeks and 6 days of gestation, for which open laparotomy was performed.

\footnotetext{
* Correspondence: chh9861@knu.ac.kr

Department of Obstetrics and Gynecology, Kyungpook National University Hospital, School of Medicine, 807 Hogukro, Buk-gu, Daegu 41404, Republic of Korea
}

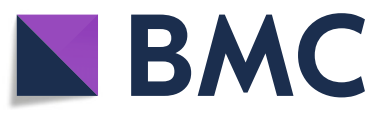

(C) The Author(s). 2019 Open Access This article is distributed under the terms of the Creative Commons Attribution 4.0 International License (http://creativecommons.org/licenses/by/4.0/), which permits unrestricted use, distribution, and

reproduction in any medium, provided you give appropriate credit to the original author(s) and the source, provide a link to the Creative Commons license, and indicate if changes were made. The Creative Commons Public Domain Dedication waiver (http://creativecommons.org/publicdomain/zero/1.0/) applies to the data made available in this article, unless otherwise stated.

\section{Case presentation}

A 28-year-old Asian woman (G3P1) who had undergone emergency cesarean delivery owing to a compound presentation at full term was referred to our institution with a suspicion of abnormally located gestational sac. She had undergone laparoscopic cholecystectomy and open appendectomy previously. She did not have any medical, family, or psychosocial history. She had missed her menstrual period without any other symptom and visited a private obstetrical clinic to confirm the pregnancy. However, she was diagnosed as having an abnormal pregnancy such as cervical or CSP by USG.

At our institution, she reported that her last menstrual period was just 5 to 6 weeks prior. However, USG revealed a gestational sac in the anterior lower uterine segment with a fetus measuring $4.83 \mathrm{~cm}$ crown-rump length (CRL) with positive cardiac activity, corresponding to 11 weeks and 6 days of gestation. Color/power Doppler images depicted a hyperechoic rim of a choriodecidual reaction with excessive vascularity (Fig. 1). Although we could observe a definitive abnormally located gestational sac, our patient did not have any pain during 


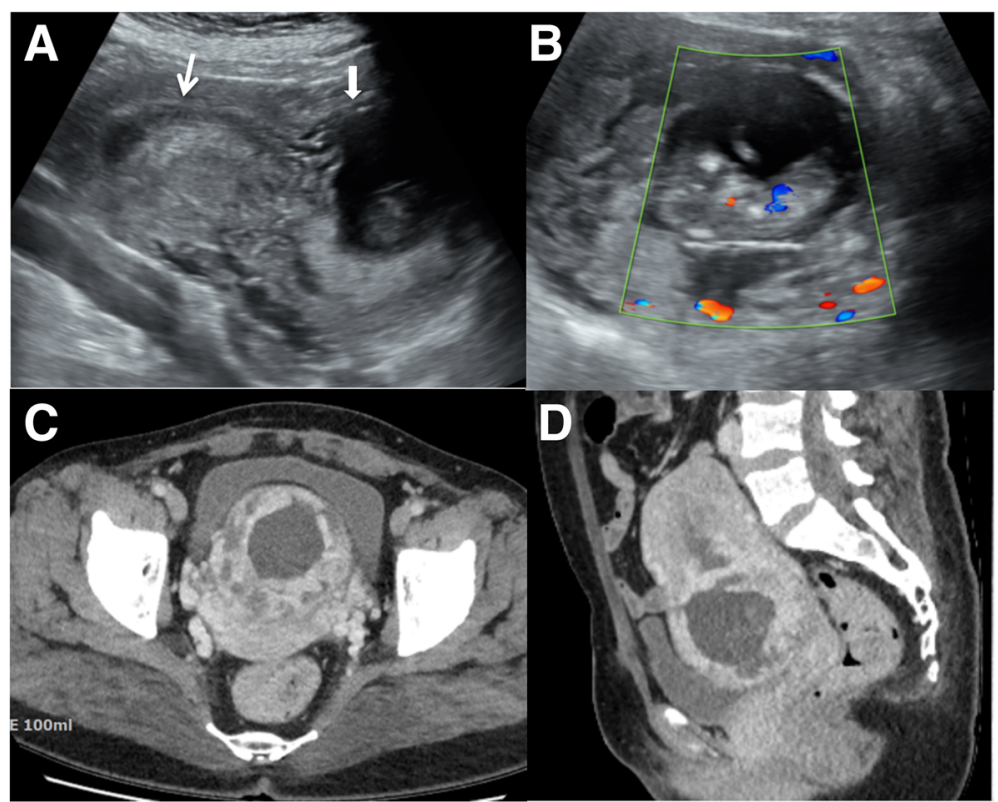

Fig. 1 The initial transabdominal ultrasonography images show a gestational sac (bold arrow) located anteriorly in the lower uterine cavity with an empty uterine endometrial cavity (narrow arrow) (a). The color/power Doppler images depict a hyperechoic rim of choriodecidual reaction with excessive vascularity (b). The computed tomography image shows an intrauterine gestational sac in the lower uterine segment bulging through the anterior uterine wall at the site of the cesarean scar without invasion of the urinary bladder (c, $\mathbf{d}$ )

the physical examination. She admitted that her last menstrual period was different from her usual menstrual periods. Because CSP or cervical pregnancy was suspected, we performed computed tomography (CT) for a definitive diagnosis. The CT scan showed an intrauterine gestational sac in the lower uterine segment bulging through the anterior uterine wall at the site of the cesarean scar. No invasion of the urinary bladder was observed (Fig. 1). On presentation, her $\beta$-human chorionic gonadotropin ( $\beta$-hCG) level was 66,536.8 IU/L (Day 1). Initially, we injected $50 \mathrm{mg}$ of methotrexate (MTX) mixed with $9 \mathrm{~mL}$ of normal saline in the amniotic sac through a 22-G needle transabdominally under USG guidance. Simultaneously, $2 \mathrm{ml}$ of amniotic fluid was aspirated for termination of the pregnancy. However, fetal cardiac activity was still observed 2 days later (Day 3), without significant changes in the serum $\beta$-hCG levels
$(65,342.5 \mathrm{IU} / \mathrm{L})$. We decided on laparotomy instead of laparoscopy because of the large CRL (Day 4). The intraoperative finding showed bloody amniotic fluid, blood clot, placenta, and a fetus at the lower segment of the uterus. A transverse uterine incision was made at the lower segment of the uterus (Fig. 2). The gestational sac was removed, as well as most of the trophoblastic tissues that were adherent and invading the wall of the lower uterine segment. The fetus and placenta showed no definitive abnormalities (Fig. 2). The estimated blood loss was $1.2 \mathrm{~L}$ at intra-operation, without immediate complication. The uterine defect was repaired into two layers by using 2-0 Vicryl sutures. Our patient received 3 units of packed red blood cells (PRBC) at the ward postoperatively. The serial $\beta$-hCG level was $1958 \mathrm{IU} / \mathrm{L}$ at 4 days after the surgery (Day 8). She was discharged in good condition 5 days after the operation (Day 9). After 1

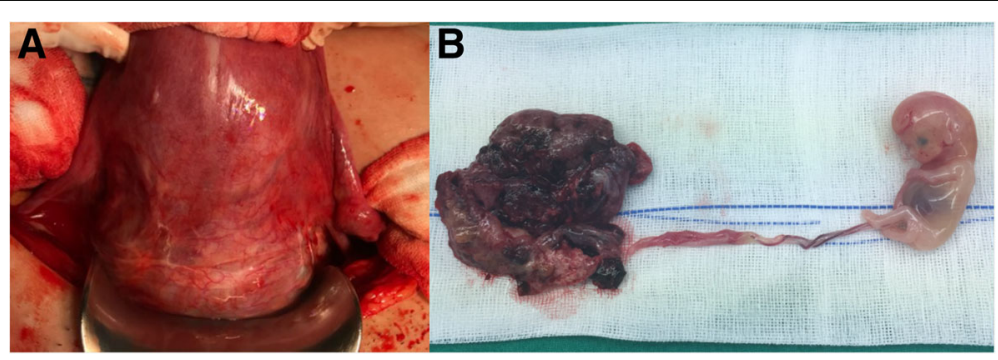

Fig. 2 Bulging lower segment of the uterus observed during open laparotomy (a). The gross finding shows the placenta and fetus measuring $6.0 \times 2.4 \mathrm{~cm}$ without other gross anomalies (b) 
month (Day 39), her $\beta$-hCG levels returned to normal $(2.8 \mathrm{IU} / \mathrm{L})$. She was very satisfied with the fact that she had recovered well without the need for intensive care or further treatment without the need for hysterectomy.

\section{Discussion}

CSP is a rare form of ectopic pregnancy. Its exact pathogenesis is unknown, but attributing factors have been thought to include endometrial and myometrial disruption or defects, or microscopic isolation between the cesarean scar and the space of the endometrium and implantation of the conceptus in the myometrium through the tract by the invading blastocyst $[3,4]$. Based on imaging findings and progress reports during pregnancy, CSP is divided into two types: type 1 and 2 . In type 1 CSP (endogenic type), implantation occurs on the scar site and the gestational sac grows toward the cervico-isthmic or uterine cavity. Type 2 CSP (exogenic CSP) occurs when the gestational sac is deeply embedded in the scar and the surrounding myometrium, and grows toward the urinary bladder. Although the exogenic type of CSP carries a greater risk of earlier uterine rupture, several cases of viable birth following the diagnosis of the endogenic type of CSP have been reported $[5,6]$. However, expectant management of CSP that leads to live birth at the late preterm period is known to be associated with severe maternal morbidity such as massive hemorrhage, uterine rupture, or hysterectomy [7]. Our case was an endogenic type of CSP; therefore, it could continue until 12 weeks of gestation without uterine rupture. However, we decided to terminate the pregnancy owing to the consideration of maternal morbidity.

Earlier detection and appropriate management of CSP are important. Transvaginal USG is extremely helpful in the diagnosis of CSP with the following criteria: an empty endometrial cavity and cervical canal, a gestational sac in the anterior uterine wall, and prominent trophoblastic/placental blood flow [1-3]. Magnetic resonance imaging (MRI) is superior in the assessment of pelvic structures because of improved differentiation of soft tissue, spatial resolution, and the possibility of multiplanar imaging. Sagittal and transverse T1-weighted and T2-weighted MRI sequences can clearly show the gestational sac embedded in the anterior lower uterus. Furthermore, the T2-weighted sagittal section is the best view for the cesarean section scar, gestational sac, and decidual layer of a CSP [8]. However, MRI takes a long time to perform and does not require serial follow-up; therefore, many clinicians prefer USG. Despite these diagnostic tools, diagnosis of CSP is still delayed. In this case, she had mistaken abnormal vaginal bleeding for normal menstrual cycle. Therefore, the diagnosis was delayed until 12 weeks of gestation.
Although the incidence of CSP has increased in recent decades, a definitive treatment modality has not been established yet [4]. The treatment of CSP should be individualized on the basis of the clinical presentation, gestational age, type of pregnancy on imaging, and fertility preservation. Medical treatment using MTX is usually attempted systemically or locally before surgical treatment $[7,9,10]$. Previous studies have reported that an earlier gestational age and faster diagnosis result in a higher success rate of conservative treatments with MTX [5, 11, 12]. Local MTX therapy can increase the concentration of MTX in one area and reduce side effects compared to systemic therapy [13]. Systemic MTX therapy seems to be relatively effective in patients with $\beta$-hCG levels of $<5000 \mathrm{IU} / \mathrm{L}$ [14]. Surgical treatment is not recommended except in cases where the conservative treatment fails due to high morbidity and poor prognosis or in cases of uterine rupture due to late diagnosis [15]. Dilation and curettage, vacuum extraction method, hysteroscopy, laparoscopy, and laparotomy can be operative treatment options [16-19]. Recent reports have suggested that hysteroscopy offers little benefit when compared with curettage alone [20]. Laparoscopic procedures should be performed by a highly skilled surgeon, and vasopressin injection or laparoscopic coagulation or ligation of the uterine artery may be used to reduce bleeding [21]. Interventional radiological techniques such as uterine artery embolization have been successfully used. One of the serious complications of uterine artery embolization is pulmonary embolism. As pulmonary embolism is rare but life-threatening, obstetricians should be aware of the potential for serious complications after uterine artery embolization procedures and should evaluate the risk of embolization as a treatment option [22]. Also, because our patient has only one living child, we chose laparotomy instead of uterine artery embolization in this case.

In this case, the diagnosis of CSP was delayed and thus the risk of bleeding was higher. There was no established definition of advanced or delayed diagnosed CSP. However, in most previous reports, CSP was diagnosed between 6 and 8 weeks of gestation [2, 3, 5, 8]. Therefore, we had difficulty in choosing the treatment option. To reduce the possibility of maternal morbidity, we locally injected MTX with aspiration of amniotic fluid. We assumed that the procedure would help reduce the risk of bleeding.

\section{Conclusion}

Although the diagnosis of CSP is rarely delayed, its treatment is important because it can be life-threatening. However, no treatment for CSP has been established and few cases have been reported. More cases and multicenter cohort studies are needed, and laparotomy with local MTX injection may be a treatment option. 


\section{Abbreviations}

CRL: Crown-rump length; CSP: Cesarean scar pregnancy; CT: Computed tomography; MRI: Magnetic resonance imaging; MTX: Methotrexate; PRBC: Packed red blood cells; USG: Ultrasonography; $\beta$-hCG: $\beta$-human chorionic gonadotropin

\section{Acknowledgements}

The authors have no commercial, proprietary, or financial interest in the products and companies described in this article.

\section{Funding}

The authors received no specific funding for this study.

\section{Availability of data and materials}

All data generated or analyzed during this study are included in this manuscript. The datasets during and/or analyzed during the current study are available from the corresponding author on reasonable request.

\section{Authors' contributions}

EJJ wrote the report and HHC revised the report. WJS contributed to the management of the patient. All authors read and approved the final manuscript.

\section{Ethics approval and consent to participate}

Not applicable.

\section{Consent for publication}

Written informed consent was obtained from the patient for publication of this case report and any accompanying images. A copy of the written consent is available for review by the Editor-in-Chief of this journal.

\section{Competing interests}

The authors declare that they have no competing interests.

\section{Publisher's note}

Springer Nature remains with regard to jurisdictional claims in published maps and institutional affiliations.

Received: 11 June 2018 Accepted: 16 January 2019

Published online: 07 March 2019

\section{References}

1. Tamada S, Masuyama H, Maki J, Eguchi T, Mitsui T, Eto E, et al. Successful pregnancy located in a uterine cesarean scar: A case report. Case Rep Womens Health. 2017;14:8-10.

2. Seow KM, Huang LW, Lin YH, Lin MY, Tsai YL, Hwang JL. Cesarean scar pregnancy: issues in management. Ultrasound Obstet Gynecol. 2004;23(3): 247-53.

3. Nawroth F, Foth D, Wilhelm L, Schmidt T, Warm M, Romer T. Conservative treatment of ectopic pregnancy in a cesarean section scar with methotrexate: a case report. Eur J Obstet Gynecol Reprod Biol. 2001;99(1): 135-7.

4. Qian ZD, Guo QY, Huang LL. Identifying risk factors for recurrent cesarean scar pregnancy: a case-control study. Fertil Steril. 2014;102(1):129-34. e1

5. Vial Y, Petignat $P$, Hohlfeld P. Pregnancy in a cesarean scar. Ultrasound Obstet Gynecol. 2000;16(6):592-3.

6. Timor-Tritsch IE, Monteagudo A, Cali G, Vintzileos A, Viscarello R, Al-Khan A, et al. Cesarean scar pregnancy is a precursor of morbidly adherent placenta. Ultrasound Obstet Gynecol. 2014;44(3):346-53.

7. Hasegawa J, Ichizuka K, Matsuoka R, Otsuki K, Sekizawa A, Okai T. Limitations of conservative treatment for repeat Cesarean scar pregnancy. Ultrasound Obstet Gynecol. 2005;25(3):310-1.

8. Peng KW, Lei Z, Xiao TH, Jia FG, Zhong WX, Gao Y, et al. First trimester caesarean scar ectopic pregnancy evaluation using MRI. Clin Radiol. 2014; 69(2):123-9.

9. Lee JH, Kwon DH, Ahn KH, Hong SC, Kim T. Concomitant ultrasound-guided intra-gestational sac methotrexate-potassium chloride and systemic methotrexate injection in the recurrent cesarean scar pregnancy. Obstet Gynecol Sci. 2016;59(3):245-8.
10. Ben Nagi J, Ofili-Yebovi D, Sawyer E, Aplin J, Jurkovic D. Successful treatment of a recurrent Cesarean scar ectopic pregnancy by surgical repair of the uterine defect. Ultrasound Obstet Gynecol. 2006;28(6):855-6.

11. Rempen A. An ectopic pregnancy embedded in the myometrium of a previous cesarean section scar. Acta Obstet Gyn Scan. 1997;76(5):492.

12. Feichtinger $W$, Kemeter $P$. Conservative treatment of ectopic pregnancy by transvaginal aspiration under sonographic control and methotrexate injection. Lancet. 1987;1(8529):381-2.

13. Schiff E, Shalev E, Bustan M, Tsabari A, Mashiach S, Weiner E. Pharmacokinetics of methotrexate after local tubal injection for conservative treatment of ectopic pregnancy. Fertil Steril. 1992;57(3):688-90.

14. Demirdag E, Guler I, Abay S, Oguz Y, Erdem M, Erdem A. The impact of expectant management, systemic methotrexate and surgery on subsequent pregnancy outcomes in tubal ectopic pregnancy. Ir J Med Sci. 2017;186(2): 387-92.

15. Lai YM, Lee JD, Lee CL, Chen TC, Soong YK. An ectopic pregnancy embedded in the myometrium of a previous cesarean section scar. Acta Obstet Gynecol Scand. 1995;74(7):573-6.

16. Wu X, Xue X, Wu X, Lin R, Yuan Y, Wang Q, et al. Combined laparoscopy and hysteroscopy vs. uterine curettage in the uterine artery embolizationbased management of cesarean scar pregnancy: a cohort study. Int J Clin Exp Med. 2014;7(9):2793-803.

17. Shao MJ, Hu M, Hu MX. Conservative management of cesarean scar pregnancy by local injection of ethanol under hysteroscopic guidance. Int J Gynaecol Obstet. 2013;121(3):281-2.

18. Robinson JK, Dayal MB, Gindoff P, Frankfurter D. A novel surgical treatment for cesarean scar pregnancy: laparoscopically assisted operative hysteroscopy. Fertil Steril. 2009;92(4):1497. e1413-1496

19. Sel G, Sucu S, Harma M, Harma MI. Successful management of cesarean scar pregnancy with vacuum extraction under ultrasound guidance. Acute Med Surg. 2018;5(4):358-61.

20. Qian ZD, Huang LL, Zhu XM. Curettage or operative hysteroscopy in the treatment of cesarean scar pregnancy. Arch Gynecol Obstet. 2015;292(5): 1055-61.

21. Fuchs N, Manoucheri E, Verbaan M, Einarsson Jl. Laparoscopic management of extrauterine pregnancy in caesarean section scar: description of a surgical technique and review of the literature. BJOG. 2015:122(1):137-40.

22. Qiu J, Fu Y, Huang X, Shu L, Xu J, Lu W. Acute pulmonary embolism in a patient with cesarean scar pregnancy after receiving uterine artery embolization: a case report. Ther Clin Risk Manag. 2018;14:117-20.

\section{Ready to submit your research? Choose BMC and benefit from:}

- fast, convenient online submission

- thorough peer review by experienced researchers in your field

- rapid publication on acceptance

- support for research data, including large and complex data types

- gold Open Access which fosters wider collaboration and increased citations

- maximum visibility for your research: over $100 \mathrm{M}$ website views per year

At BMC, research is always in progress.

Learn more biomedcentral.com/submissions 